\title{
A Foray into Fauré
}

\section{by Megan Chellew}

Two summers ago, I received a request to rush catalogue a manuscript score that was needed for an exhibition. I'm not entirely sure what I was expecting, but I was not expecting the manuscript in question to be a song by Gabriel Fauré. What followed was the most interesting, and exciting, day of cataloguing I have ever experienced.

I had catalogued many scores before, and facsimiles of manuscript scores, but never an actual manuscript, and certainly not using RDA. So I began my cataloguing journey with some trepidation. I quickly discovered, however, that cataloguing a manuscript (or perhaps it would be more accurate to say cataloguing this particular manuscript) was more straightforward than I had expected.

I've developed my own technique for cataloguing any rare item - whether a book, a score, or a graphic. I call it "red carpet" level cataloguing. I assume that the item in hand is unique, and therefore deserving of the most special treatment. I took this approach with the Faure score, and asked it my three standard red carpet interview questions:

1. Who are you?

2. How did you get here?

3. What are you wearing?

\section{Who are you?}

When I ask this question, I'm really asking the manuscript to provide me with as many elements of the bibliographic description as it can. For me, that begins with "what is your name?" and "who created you?" In this case, the manuscript has a title page:

Megan Chellew (megan.chellew@mcgill.ca) is Coordinator of the Cataloguing \& Metadata unit at the McGill University Library. She and her team catalogue music, rare books, and "all things cool." 


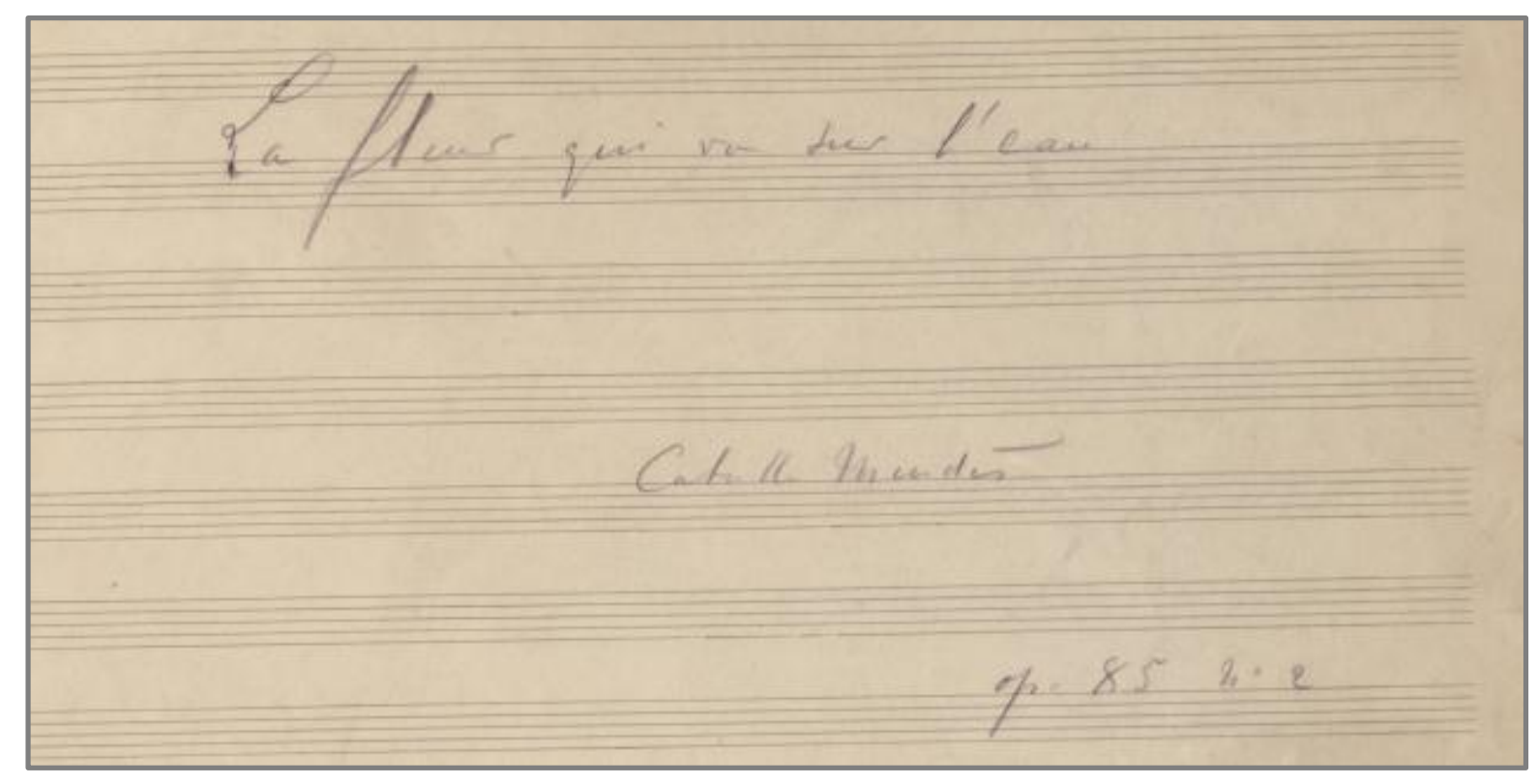

The beginning of the answer, therefore, is that this is a manuscript titled "La fleur qui va sur l'eau" and that it is op. 85 no. 2 . The title page also provides the name "Catulle Mendès" — the song is a musical setting of one of his poems.

No credit is given to Fauré on the title page, but I know (from RDA 2.4.2.2) that when there is no statement of responsibility on the same source as the title proper (i.e. when the composer's name doesn't appear on the title page), I can take that information from elsewhere in the resource. In this case, the manuscript is helpfully signed (and dated) at the end:

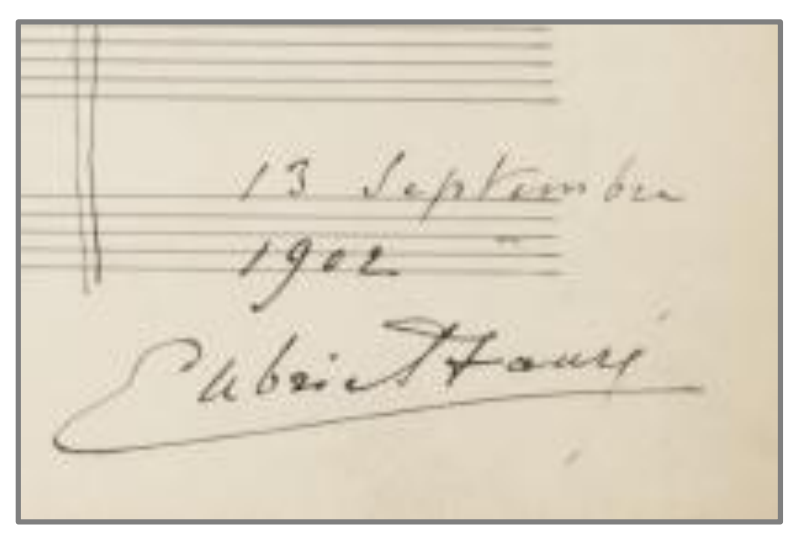

Working from just those two sources, I can build several MARC fields for my record:

\begin{tabular}{|c|c|c|c|}
\hline 100 & 1 & & Fauré, Gabriel, ¥d 1845-1924, ¥e composer. \\
\hline 240 & 1 & 0 & Mélodies, $\neq n$ op. 85. $\neq p$ Fleur qui va sur l'eau \\
\hline 245 & 1 & 3 & La fleur qui va sur l'eau : ¥b op. 85, no. 2 / łc Gabriel Fauré ; [poésie de] Catulle Mendès. \\
\hline
\end{tabular}


The 100 and 240 fields are the authorized forms of name and title from the Authority File. The 245 field is a faithful transcription of the title page (RDA 2.3.1.4), and I added Fauré's name, as well as the square bracketed [poésie de] to clarify Mendès's role (RDA 2.4.1.7). I could have reversed Fauré and Mendès in the 245, but I decided that it made more sense to record the composer first (RDA 2.4.1.6).

The next part of my "who are you" question is asking for more personal information: "when and where were you created?" We saw above that the manuscript is signed and dated, so I know the manuscript was produced in 1902 (September 13th, to be precise), and it was produced by Fauré himself. There's no indication of where the manuscript was produced, but an educated guess would be France (I could even guess it was produced in Paris, but France is a safer choice). With this information, I can expand my MARC record:

\begin{tabular}{|c|c|c|c|}
\hline 100 & 1 & & Fauré, Gabriel, ¥d 1845-1924, ¥e composer. \\
\hline 240 & 1 & 0 & Mélodies, $\neq n$ op. 85 . $\neq p$ Fleur qui va sur l'eau \\
\hline 245 & 1 & 3 & La fleur qui va sur l'eau : ¥b op. 85, no. 2 / ₹c Gabriel Fauré; [poésie de] Catulle Mendès. \\
\hline 264 & & 0 & [France] : ¥b [Gabriel Fauré], \#c 1902. \\
\hline
\end{tabular}

The 264 field has a second indicator 0 , showing that the information in the field relates to the production of the score (as opposed to the publishing, printing, or copyright). The square bracketed [France] shows that the information is inferred. It could also be recorded as "[France?]" with a question mark, but I felt secure enough in my educated guess to go without the question mark. The square bracketed [Gabriel Fauré] is something I would probably do differently if I were cataloguing this today. The manuscript is signed; I'm not inferring that Fauré is the producer, so the square brackets aren't technically necessary.

Now I ask the manuscript for information of an even more personal nature. In cataloguing language, I would ask "what are your physical dimensions?" This seems somewhat akin to asking someone how much they weigh...luckily most things I catalogue aren't offended by that kind of question. In the bibliographic universe, the information I'm looking for is the extent (pagination) and the dimensions (height, etc.) of the manuscript. The pages aren't numbered, but they are easily countable - there are 10 . And the height of the manuscript is $35 \mathrm{~cm}$, so with these pieces of information I can add another field to my record: 


\begin{tabular}{|c|c|c|c|}
\hline 100 & 1 & & Fauré, Gabriel, ¥d 1845-1924, ¥e composer. \\
\hline 240 & 1 & 0 & Mélodies, $\neq n$ op. 85. ¥p Fleur qui va sur l'eau \\
\hline 245 & 1 & 3 & La fleur qui va sur l'eau : ¥b op. 85, no. 2 / ¥c Gabriel Fauré ; [poésie de] Catulle Mendès. \\
\hline 264 & & 0 & [France] : \#b [Gabriel Fauré], \#c 1902. \\
\hline 300 & & & 1 score (10 unnumbered pages) ; $\neq c 35 \mathrm{~cm}$ \\
\hline
\end{tabular}

I've specified that the pages are unnumbered (the old practice under AACR2 would have been to record the number of pages in square brackets). And there is no period at the end of the field, because $\mathrm{cm}$ is now considered a symbol and not an abbreviation.

That generally takes me to the end of the "who are you" question, although along the way l've made several mental notes about other information that I'll put in the record later.

\section{How did you get here?}

In cataloguing language, this question could translate to "what is your provenance?" In other words, how did this score get from Fauré to McGill? Approaching the question of provenance can be very tricky, and sometimes incredibly frustrating. I've almost always found it easiest to work backwards. Inside the front cover of the score, is this:

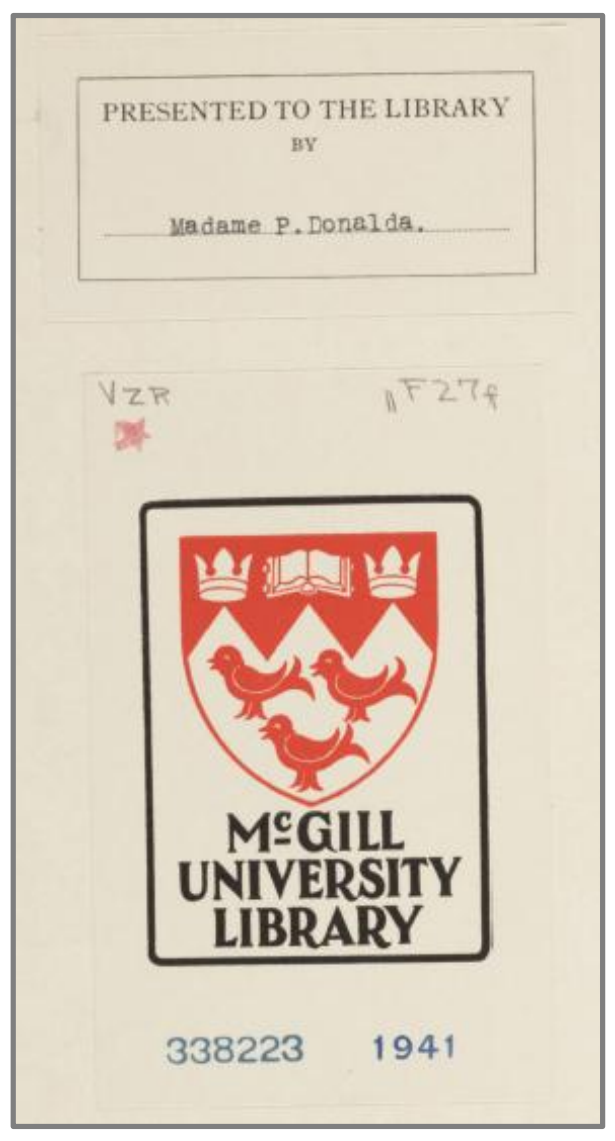


This tells me how the manuscript came to McGill (or the "immediate source of acquisition"). Pauline Donalda (1882-1970) was a highly regarded operatic soprano from Montreal. She had a performing career in Europe, and a teaching studio in Paris, and returned to Montreal in 1937 where she later founded the Opera Guild of Montreal. ${ }^{1}$ The McGill University bookplate is stamped with an accession date of 1941 . That might be the date she presented the manuscript to the Library, but it isn't necessarily safe to assume it was accessioned the same year it was received. When I catalogued the manuscript, I didn't include the date as part of the acquisition information; if I were cataloguing the manuscript today, I likely would include it, possibly with a question mark. This information adds a new field to my record:

541 Presented to McGill University Library by Pauline Donalda, with label "Presented to the Library by Madame P. Donalda"-page 2 of cover.

The 541 field is a "local" field, which wouldn't normally be included in a master record. However in this case, because the manuscript is unique, it does belong there. The 541 is a freetext field, so the information in it can be either transcribed from the source, or paraphrased. In this case, I decided to do a bit of both. I transcribed the label, but also used a slight paraphrase, to include the fuller form of Madame Donalda's name. It would have been perfectly acceptable to just transcribe the label. It would also have been perfectly acceptable to describe the information on the label (which is probably what I would do today). The important thing is to convey the information in a clear and useful way.

To further trace the provenance of the manuscript, the next question to ask is how it came to be in Pauline Donalda's possession. Happily, that information is available on the title page:

1. The Canadian Encyclopedia, s.v. "Pauline Donalda," accessed April 26, 2016, http://www.thecanadianencyclopedia.ca/en/article/pauline-donalda/. 
M. Hasselmans is Louis Hasselmans (1878-1957), a French opera conductor who directed the French operas for the Montreal Opera Company in 1911-1912. ${ }^{2}$ Further research would be needed to determine the exact relationship between Donalda and Hasselmans. It seems likely that he conducted her, but the depth of research I undertook in the cataloguing of the manuscript didn't prove this. However, M. Hasselmans has provided me with enough information for the next link in the chain of provenance:

561 Presented to Pauline Donalda by M. Hasselmans, with inscription: "Pour ma chère Pauline Donalda en souvenir M. Hasselmans 17 mai 1927"--upper centre of title page, blue ink.

In this case, I also provided information about where in the manuscript the inscription is located, as well as the fact that it's written in blue ink. Strictly speaking, neither was necessary (doing so is more in line with descriptive bibliography practices than with cataloguing rules), but since it required very little extra work to include it, I thought it was worthwhile.

And (as so often happens), that's as far as I was able to trace the provenance. There's a gap between 1902, when the song was composed, and 1927, when Hasselmans gave the manuscript to Donalda. In my experience of cataloguing rare books, gaps in provenance are far from uncommon, and a gap of only 25 years is actually pretty good. In this case, it seems possible that the manuscript passed directly from Fauré to Hasselmans, but it is possible that there was an intermediary step. One of the greatest challenges of cataloguing rare materials is learning where to draw the line in terms of ferreting out information. I drew the line here (as I did with trying to establish the direct link between Hasselmans and Donalda), and moved on to my next question.

\section{What are you wearing?}

The gist of this question might be less obvious than my first two red carpet questions, but what I'm asking here is for information about the binding. Sometimes the answer is very complex, including information about endpapers, side-edges, spine decorations, etc., etc. In this case, however, the binding is not especially interesting. It is standard blue cloth binding over boards. From the date on the bookplate inside the cover, we can infer that it was bound sometime before 1941, but there's no more specific information about when or who the binder was. The one interesting fact-which briefly had me thinking I had stumbled upon a previously unknown manuscript-is that the binder misspelled the title on the cover label:

2. The Canadian Encyclopedia, s.v. "Montreal Opera Company/Compagnie d'opéra de Montréal," accessed April 26, 2016, http://www.thecanadianencyclopedia.ca/en/article/montreal-opera-companycompagnie-doperade-montreal-emc/. 


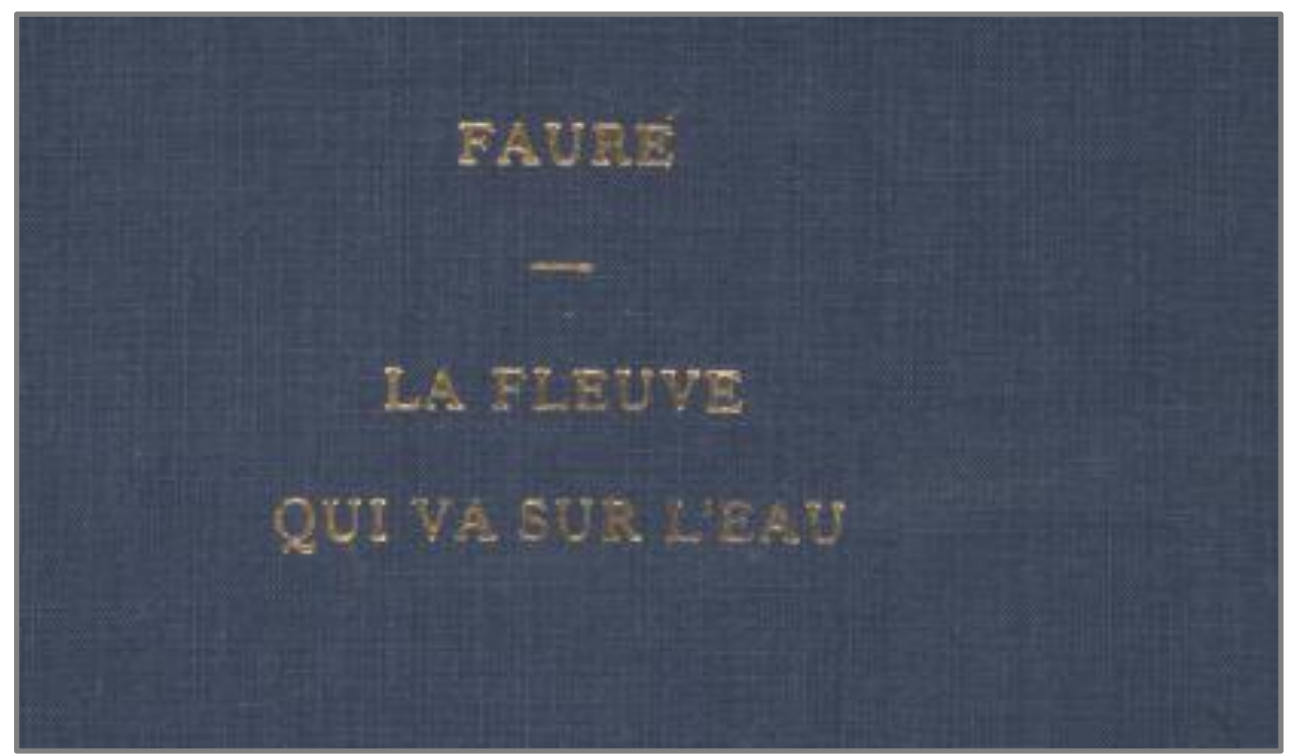

I immediately leapt to the conclusion that this had been mis-catalogued for decades, and therefore scholars would have been completely unable to locate it. But, sadly for me, albeit happily for scholars, that was not the case. It did, however, make my note describing the binding slightly more interesting:

$563 \quad$ Bound in blue cloth over boards, with binder's title "Fauré - La fleuve qui va sur l'eau".

And I also added a Varying Form of Title field, in case anyone looked for it by binder's title:

$2461 \quad \neq i$ Binder's title: $\neq$ a Fauré - La fleuve qui va sur l'eau

Admittedly, the chances of anyone browsing for this by the binder's title are very slim, so including a 246 field (which means the variant title will be included in the same index as proper titles) likely doesn't increase the findability of the manuscript. What it does accomplish, however, is a clear display in the public interface of the catalogue, so the variant title isn't buried in the note describing the binding.

\section{Other parts of the record}

To enhance my record, I tucked in other details that didn't really belong in any of the fields I've used so far. For any manuscript, the first general note is exactly that:

$500 \quad$ Manuscript.


The next note, which is specific to music cataloguing, provides information about who, or what, the piece is written for:
500
For high voice and piano.

After that, I added a note describing the title page:

500 "La fleur qui va sur l'eau, op. 85, no. 2, Catulle Mendès"--title page, centre, purple pencil.

Once again, this is not really necessary, it's just me going the extra mile. And so is the next note, describing how the manuscript is signed:

\section{$500 \quad$ "13 septembre 1902 Gabriel Fauré"--at end of music, black ink.}

The next note, however, is pretty special, and not an example of just going the extra mile. When Fauré was dashing off this manuscript, he left out a bar of music, and had to tip in an extra bar that folds out from page 8 :

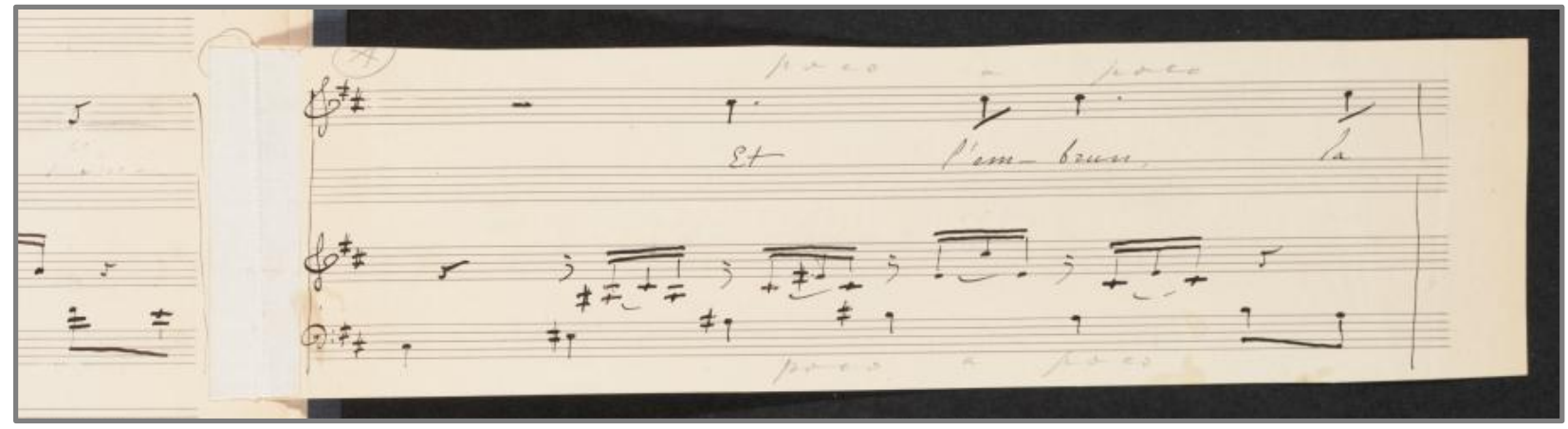

This was definitely worth mentioning, both because it is interesting in and of itself, but also because it's important to record things that are inserted or added. There is now a permanent record of the fact that this bar was added; if something ever happens to the manuscript...if somehow that addendum walks off...mentioning it in the cataloguing record is one form of proof that it existed in the first place:
500 Added measure tipped in on page 8 . 
In addition to adding these general notes about the manuscript, I also added a suite of subjectrelated fields:

\begin{tabular}{|lrll|}
\hline 600 & 1 & 0 & Fauré, Gabriel, $\neq d$ 1845-1924 ¥v Manuscripts. \\
600 & 1 & 0 & Mendès, Catulle, $\neq d$ 1841-1909 ¥v Musical settings. \\
650 & 0 & Songs (High voice) with piano. \\
650 & 0 & Music ¥x Manuscripts. \\
\hline
\end{tabular}

These access points ensure that: the record will index with other Fauré manuscripts; it will index with any other musical settings of Mendès's poems; it will index with all the songs for high voice and piano; and it will index with all the music manuscripts.

I also traced all three of the "other" people associated with this manuscript:

\begin{tabular}{|llll|}
\hline 700 & 1 & Mendès, Catulle, $\neq$ d 1841-1909. \\
700 & 1 & Hasselmans, Louis, $\neq$ e former owner. \\
700 & 1 & Donalda, Pauline, $\neq d$ d 1882-1970, $\neq$ e former owner. \\
\hline
\end{tabular}

I might also have given Donalda a relationship designator of "donor" instead of (or in addition to) "former owner".

\section{Fields "just" for cataloguers}

There are also a handful of fields that likely don't have much interest for non-cataloguers, so I will include them very briefly. They are the trio of 336-337-338 fields (content, media, carrier):

\begin{tabular}{|ll|}
\hline 336 & notated music $\neq 2$ rdacontent \\
337 & unmediated $\neq 2$ rdamedia \\
338 & volume $\neq 2$ rdacarrier \\
\hline
\end{tabular}

And also the language note:

$546 \quad$ Words in French; $\neq$ b staff notation


And for cataloguers who would like to see the fixed fields:

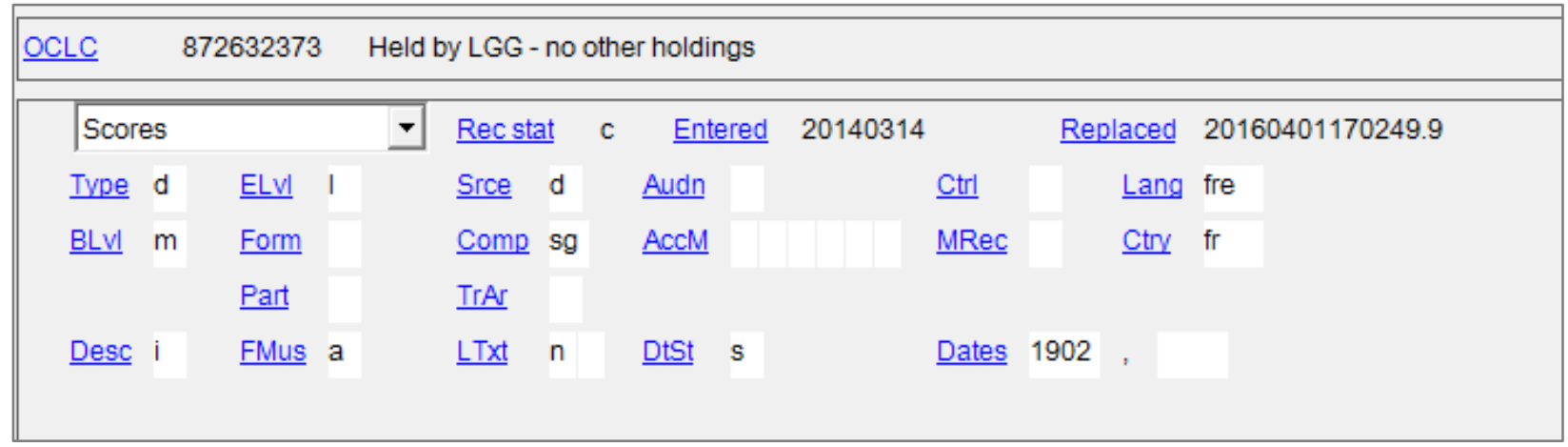

New MARC fields have been introduced since I catalogued the manuscript, so if I were cataloguing it today the record would also include a 382 field for the medium of performance.

\section{Other business}

The whole time I was cataloguing this, I had one question nagging at the back of my brain: just how special is this manuscript? Was it possible that there are many versions of this song floating around out there? What if Fauré went around dashing off manuscripts of this song for all his favourite singers, so having one isn't all that special at all? Here's what I discovered:

- The listing for op. 85 no. 2 in the Grove gives the date of composition as 13 Sept 1902, which is an exact match to the manuscript. ${ }^{3}$ So unless Faure was in the habit of handwriting multiple copies of his manuscripts all with the same date, the Grove is talking about this manuscript.

- In his Gabriel Fauré: A Guide to Research, Edward R. Phillips lists this manuscript under Primary Sources. ${ }^{4}$ It also appears to be the only Fauré manuscript located in North America. The copy in the Bibliothèque nationale de France is exactly that-a photocopy of the McGill manuscript.

So, to summarize, this is pretty special!

The manuscript has subsequently been digitized, and is available here:

http://digitool.library.mcgill.ca/webclient/DeliveryManager?\&pid=122873

3. Jean-Michel Nectoux, "Fauré, Gabriel," in Grove Music Online, Oxford Music Online, accessed April 26, 2016, http://www.oxfordmusiconline.com/subscriber/article works/grove/music/09366\#S09366.4.2.

4. Edward R. Phillips, Gabriel Fauré: A Guide to Research (New York: Garland, 2000), 58-59. 
As I said earlier, these 10 unnumbered pages (plus unprepossessing binding) provided me with one very exciting day of cataloguing at the time, and many exciting conversations since. Writing this article has given me the opportunity to relive that day. It has also given me the rare opportunity to revisit, and reevaluate, my own cataloguing -in general, doubling back and "recataloguing" is not feasible, except to correct errors. I did find two errors in my record which I corrected but didn't mention in the article (one was silly, one was somewhat horrifying). Other than that, the record stands as I created it. I've noted throughout the article things that I could or would do differently if I had a second chance to catalogue this (especially as RDA evolves and affords more or different possibilities for cataloguing). In the end, I've learned a couple of things from the experience. My red carpet cataloguing technique held up well; and, even though I might make different decisions about various things today, the decisions I made at the time are decisions I can stand behind.

At the end of the day, we catalogue to share. The purpose of the MARC record is to reflect the manuscript, and share it with those who are interested. And the purpose of this article is to reflect on the day of cataloguing and the process of cataloguing, and share it with those who are interested. And of course, by extension, to share this wonderful manuscript with the world. 